\title{
Comparison of Different Scoring Systems in Poisoning With Cholinesterase Inhibitors
}

\author{
Marwa M. Shahin ${ }^{1}$, Amal S. A. F. Hafez ${ }^{1 *}$
}

\begin{abstract}
KEYWORDS

Acute physiology and chronic health evaluation II score; Cholinesterase inhibitors; Glasgow Coma Scale;

Mortality;

Rapid acute physiology score;

Rapid emergency medicine score;

Simple clinical score.

Early identification of cholinesterase inhibitor (AChEI) - poisoned patients who are at risk of respiratory insufficiency or death is crucial to initiate proper interventions. The present study aimed to compare Glasgow Coma Scale (GCS), acute physiology and chronic health evaluation (APACHE II), rapid acute physiology score (RAPS), rapid emergency medicine score (REMS) and simple clinical score (SCS) in order to predict the need of mechanical ventilation (MV) and the risk of mortality in AChEIs poisoning. A retrospective study was conducted on 118 patients with acute AChEIs poisoning. The patients' data were collected from their hospital records. The studied scoring systems were evaluated on admission. Statistical analysis revealed that the median APACHE II, GCS, REMS, RAPS, and SCS differed significantly between MV patients and non-MV as well as between non-survivors and survivors. RAPS and REMS scores showed the highest discriminatory power in prediction of MV and mortality. No significant differences were detected between the studied scores as predictors of MV and mortality except for SCS which was significantly inferior to RAPS and REMS in prediction of MV. In conclusion, the admission REMS or RAPS seem to have valuable prognostic abilities in AChEIs poisoning for identification of patients who require MV or at increased risk of mortality.
\end{abstract}

\section{Introduction}

Cholinesterase inhibitors (AChEIs)
comprise two main categories: organophosphorous compounds (OPCs) and carbamates; these agents are used mainly as pesticides. Most cases of poisoning result from exposure to insecticides and rodenticides. In addition, OPCs are present as an active constituent in nerve gases (such as soman, sarin and, tabun), ophthalmic agents (such as echothiophate and isoflurophate), and antihelmintics (trichlorfon) (Konradsen, 2007).

\footnotetext{
${ }^{(1)}$ Forensic Medicine and Clinical Toxicology Department. Tanta Faculty of Medicine, Tanta University, Gharbia, Egypt.

*Corresponding author: amal.hafez@med.tanta.edu.eg
}

Carbamates are included in drug design and drug industry (Ghosh and Brindisi, 2015).

Acute pesticide poisoning with AChEIs represents a serious public health problem worldwide; resulting in 200,000 deaths annually - the majority of which are caused by OPCs ingestion (Buckley et al., 2011).

Egypt is predominantly an agricultural country; therefore, pesticides are abundantly used during cultivation. Lack of strict control over the sale and handling of pesticides renders them easily accessed by individuals who attempt suicide (Suliman et al., 2006).

Poisoning with AChEIs represents one of the major health concerns in developing countries (Konradsen, 2007; Paudyal, 2008; Akdur et al., 2010). This also has been a great concern to developed countries which are 
vulnerable to terrorist or military attacks with nerve agents (Buckley et al., 2004).

Both OPCs and carbamates exert their action through the inhibition of cholinesterase enzyme; either reversibly in the case of carbamates or irreversibly as OPCs do. Inhibition of cholinesterase enzyme results in the accumulation of acetylcholine at synapses and neuromuscular junctions and over stimulation of acetylcholine receptors (Khurana and Prabhakar, 2000). The major reason for death is cardiorespiratory failure (Konradsen, 2007; Paudyal, 2008; Akdur et al., 2010). Identifying patients with significant poisoning and providing them with appropriate therapy is crucial for improving outcome (Peter et al., 2013).

Scoring systems are used commonly in medical practice to support clinical decisionmaking. They enable the physicians to diagnose diseases, assess patients' conditions, stratify risk, and predict the outcome (Oprita et al., 2014). Some scoring systems are based on anatomical areas (such as the injury severity score); some are organ specific [such as sepsisrelated organ failure assessment (SOFA)]; some are based on assessment of routinely measured physiological variables [such as acute physiology and chronic health evaluation (APACHE) and simplified acute physiology score (SAPS)]; and some are simple scores that are based on clinical judgment, such as Glasgow Coma Scale (GCS) (Oprita et al., 2014).

Scoring systems that are used in the emergency settings tend to be simple and based mainly on clinical data with no or minimal incorporation of investigations. Many scores have been developed and validated for use in emergency department, including rapid acute physiology score (RAPS), rapid emergency medicine score (REMS), simple clinical score (SCS), and Early Warning Score (EWS) (Brabrand et al., 2010).
However, most studies that evaluated poisoned patients with AChEIs have utilized scores that combined several parameters and that may not be applicable or available at the time of admission of poisoned patients to the emergency department.

This study aimed to compare different scoring systems as predictors of the need of mechanical ventilation (MV) and risk of mortality in patients with AChEIs poisoning.

\section{Methods}

\section{Study Design}

This retrospective study was conducted by reviewing hospital files of AChEIspoisoned patients that were admitted to Tanta University Poison Control Center (TUPCC), Tanta university hospital, during the period from the first of June 2014 to the 31st of May 2016. Tanta University hospital is a tertiary health care hospital that is located in Tanta, the principal city in Gharbia governorate, Egypt. Being in the middle of the Nile Delta, Tanta University hospital receives patients from not only Gharbia but also from the adjoining governorates such as Bahira, Menoufia and Kafr El-Shiekh.

\section{Ethical considerations}

Ethical approval was obtained from the Research Ethics Committee of Faculty of Medicine, Tanta University (Approval code: $31918 / 11 / 17)$. This study was conducted in accordance with the World Medical Association Declaration of Helsinki. Patients' coding was used to maintain confidentiality of data.

\section{Study protocol}

Inclusion criteria:

All symptomatic patients aged above 16 years old who were diagnosed with acute AChEIs poisoning were included in this study. Diagnosis based on history taking, clinical 
examination of the patients, serum activity of butyrylcholinesterase, and exclusion of relevant differential diagnoses.

\section{Exclusion criteria:}

Patients were excluded if they had comorbid associated disorder as heart, renal, or liver diseases; had co -ingested or exposed to another poison simultaneously; or were admitted to another health care facility then referred to our institution.

\section{Data collection}

The datasheet consisted of four sections. The first section included sociodemographic data (age, sex, residence, and occupation), toxicological data (manner, route of exposure, and time elapsed before admission). The second section recorded the findings of physical examination. The third section included the results of laboratory investigations. The fourth section recorded the duration of hospital stay, need of intubation, and mortality.

Patients were categorized into three groups (mild, moderate, and severe poisoning) according to the grading method by Minton and Murray (1988): a) mild grade: patients suffer from fatigue, headache, blurred vision, dizziness, nausea, vomiting, excessive sweating, salivation, abdominal pain, and chest tightness; b) moderate grade: symptoms of mild poisoning are present plus muscular fasciculation, weakness, inability to walk, and miosis; and c) severe grade: symptoms of moderate poisoning are found in addition to unconsciousness, flaccid paralysis, respiratory distress, cyanosis, and marked miosis with loss of pupil reflexes.

All patients received the standard treatment, according to the guidelines of TUPCC. The treatment consisted of suction of secretions from the airway, providing supplemental oxygen and assisted ventilation as required, gastric lavage and administration of atropine and obidoxime in doses that were tailored according to the severity of poisoning and response of the patient to treatment. The decision to intubate and mechanically ventilate the patients was made by the treating toxicologists and critical care physicians when hypoxia was unresponsive to antidote and supplemental oxygen through nasal cannula or mask.

\section{Calculation of the scoring systems}

Only the recorded findings of physical examination and investigations on admission before receiving any treatment - were used to calculate the scoring systems.

The GCS was determined based on the sum of the points of eye, verbal, and motor responses. The lowest GCS is three and the maximum possible score is 15 (Teasdale and Jennett, 1974).

The APACHE II score was calculated using twelve physiological and laboratory values including temperature, mean arterial pressure, heart rate, respiratory rate, oxygenation $(\mathrm{PaO} 2$ if $\mathrm{FiO} 2<0.5$; otherwise alveolar-arterial gradient was used), arterial $\mathrm{pH}$, serum sodium, serum potassium, serum creatinine, hematocrit value, leucocytic count, and GCS. Each of these parameters was marked from zero to four, with zero being the normal and four being the most abnormal. The sum of these values was added to a mark adjusting for patient's age and a mark adjusting for chronic health problems. The minimal score is zero, while the maximal score is 71 (Knaus et al., 1985).

The RAPS was developed from APACHE II score by considering only elements that can be easily obtained in the hospital setting, these being the pulse rate, mean arterial pressure, respiratory rate, and GCS (Rhee et al., 1987). The scoring points for each variable range from zero to four. The 
minimal RAPS score is zero, while maximum score is 16. The REMS was developed as a modification of RAPS by adding peripheral oxygen saturation and chronological age. The scoring range for each variable was zero to four as RAPS, except for age that ranged from zero to six as in APACHE II score. The minimal score is zero, while the maximum score is 26 (Olsson et al., 2004).

The SCS was calculated based on seven parameters: the age, airway, breathing, circulation, disability, ECG, and fever. The minimum score is zero and the maximum score is 21 (Subbe et al., 2010).

The primary outcome measured was the discriminatory power of the studied scoring systems to predict mortality. Mortality was assessed during the hospital stay of the patients till discharge. The secondary outcomes measured included: a) the need of $\mathrm{MV}$ and b) the duration of hospital stay.

\section{Statistical analysis}

Statistical analysis was performed using MedCalc Statistical Software version 15.8. The sample size was calculated based on the assumptions that the receiver operating characteristic (ROC) curve has an area under the curve (AUC) of 0.5 in null hypothesis, the AUC of the alternative hypothesis is 0.8 , significance level at 0.05 , power at $80 \%$ and the expected ratio of negative to positive cases is 9 (based on mortality rate of $10 \%$ ). The minimum calculated sample size was 80 patients. The results of Shapiro-Wilk test showed that all quantitative data did not follow the normal distribution and hence they were summarized as median and interquartile range (expressed as 25 th percentile - 75 th percentile). Mann-Whitney U test was used to compare between two groups. Qualitative data was summarized as number and frequency of occurrence. The ROC curve was performed to analyze the relation between true-positive and false-positive results for each score. The AUC was graded as follows: $0.90-1=$ excellent; $0.80-0.90=$ good; $0.70-0.80=$ fair; and 0.60$0.70=$ poor. Pairwise comparisons were made between the AUCs of the studied scores according to the method described by DeLong et al. (1988). Significance of tests was adopted at $\mathrm{p}<0.05$ (Dawson and Trapp, 2001).

\section{Results}

This study was carried out on 118 patients diagnosed with acute AChEIs poisoning. Table (1) summarizes the sociodemographic and toxicological data of the studied patients. The age of the patients ranged from 16 to 78 years old, with a median age of 32 years. Male patients outnumbered the female $(71 \%$ versus $29 \%)$. Most patients came from rural areas (78\%). Farmers constituted $41 \%$ of cases. Nearly half the patients were exposed to AChEIs accidentally through oral or combined routes. The median delay time was four hours. The highest frequency of patients who had severe degree of poisoning was $(45 \%)$, followed by moderate degree (35\%) then mild poisoning $(20 \%)$. The hospital stay ranged from one to 48 days, with a median of two days. Patients who needed MV constituted $14 \%$ of cases and death occurred in $6 \%$ of cases.

Figure (1) demonstrates the vital signs and oxygen saturation (measured on admission) in the studied patients. Figure (2) illustrates clinical manifestations of poisoning in the studied patients. The most common presentations included nausea and vomiting $(82 \%)$, abdominal pain $(50 \%)$, hypotonia $(46 \%)$, and miosis (42\%). 


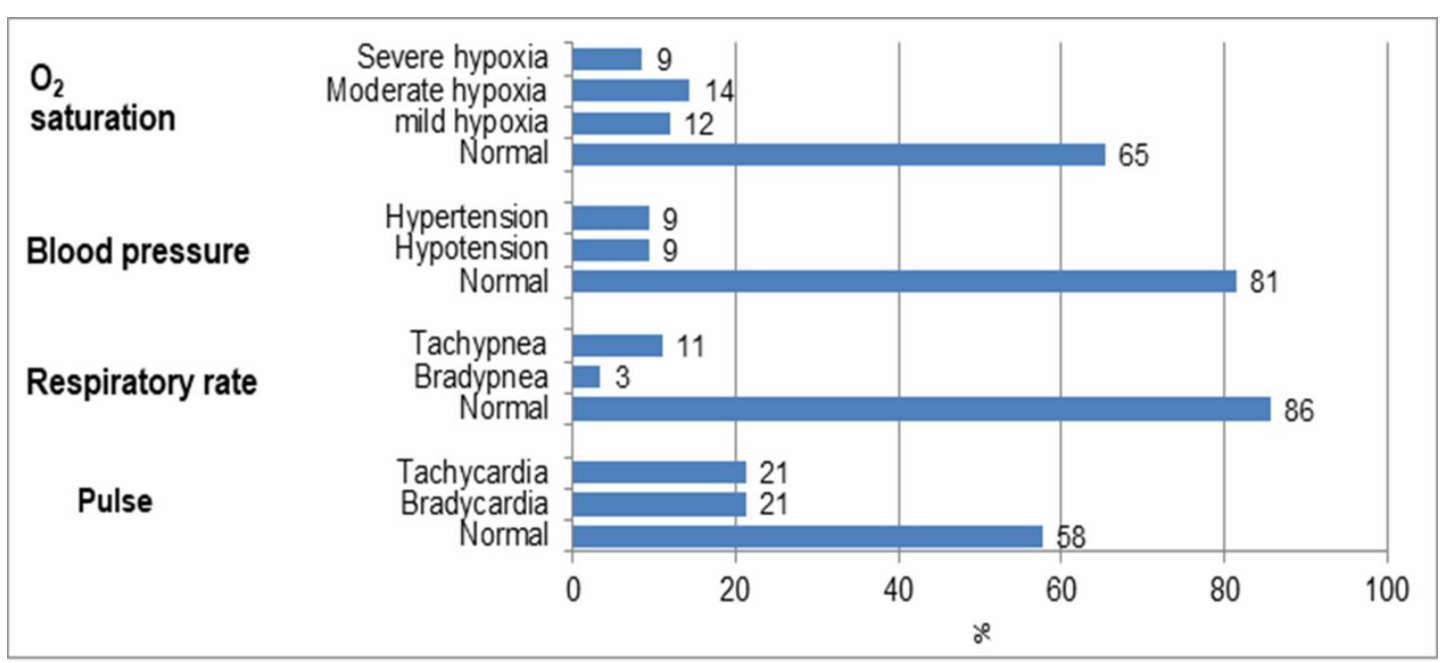

Fig. (1): Vital signs and oxygen saturation in the studied patients.

Table (1): Sociodemographic data and toxicological history of the studied patients $(n=118)$ :

\begin{tabular}{|c|c|c|c|}
\hline \multirow{3}{*}{ Age (years) } & \multicolumn{3}{|c|}{ All patients $(n=118)$} \\
\hline & Min-Max & & -78 \\
\hline & Median (IQR) & 32 & (20 to 45$)$ \\
\hline \multirow{2}{*}{ Sex n $(\%)$} & Male & 84 & $(71 \%)$ \\
\hline & Female & 34 & $(29 \%)$ \\
\hline \multirow{2}{*}{ Residence $\mathrm{n}(\%)$} & Urban & 26 & $(22 \%)$ \\
\hline & Rural & 92 & $(78 \%)$ \\
\hline \multirow{7}{*}{ Occupation n (\%) } & Student & 14 & $(12 \%)$ \\
\hline & Employee & 14 & $(12 \%)$ \\
\hline & Farmer & 48 & $(41 \%)$ \\
\hline & Unemployed & 18 & $(15 \%)$ \\
\hline & Skilled worker & 5 & $(4 \%)$ \\
\hline & Housewife & 17 & $(14 \%)$ \\
\hline & Retired & 2 & $(2 \%)$ \\
\hline \multirow{2}{*}{ Manner n (\%) } & Accidental & 60 & $(51 \%)$ \\
\hline & Suicidal & 58 & $(49 \%)$ \\
\hline \multirow{3}{*}{ Route n (\%) } & Oral & 58 & $(49 \%)$ \\
\hline & Combined & 58 & $(49 \%)$ \\
\hline & Inhalation & 2 & $(2 \%)$ \\
\hline \multirow[t]{2}{*}{ Delay (hrs) } & Min-Max & \multicolumn{2}{|c|}{$1-72$} \\
\hline & Median (IQR) & 4 & (2 to 7$)$ \\
\hline \multirow{2}{*}{ Serum butyrylcholinesterase } & Min-Max & 89 & 11485 \\
\hline & Median (IQR) & 2631 & $1185-2860$ \\
\hline \multirow{3}{*}{ Severity n (\%) } & Mild & 10 & $(20 \%)$ \\
\hline & Moderate & 17 & $(35 \%)$ \\
\hline & Severe & 22 & $(45 \%)$ \\
\hline \multirow{5}{*}{ Hospital Stay (day) } & Min-Max & \multicolumn{2}{|c|}{$1-48$} \\
\hline & Median (IQR) & 2 & $(1-2)$ \\
\hline & $1-3$ & 105 & $(89 \%)$ \\
\hline & $4-7$ & 10 & $(8 \%)$ \\
\hline & $>7$ & 3 & $(3 \%)$ \\
\hline \multicolumn{2}{|l|}{ Mechanical ventilation n (\%) } & 17 & $(14 \%)$ \\
\hline \multicolumn{2}{|l|}{ Mortality n (\%) } & 7 & $(6 \%)$ \\
\hline
\end{tabular}

n: number; Min: minimum; Max: maximum; IQR: interquartile range. 


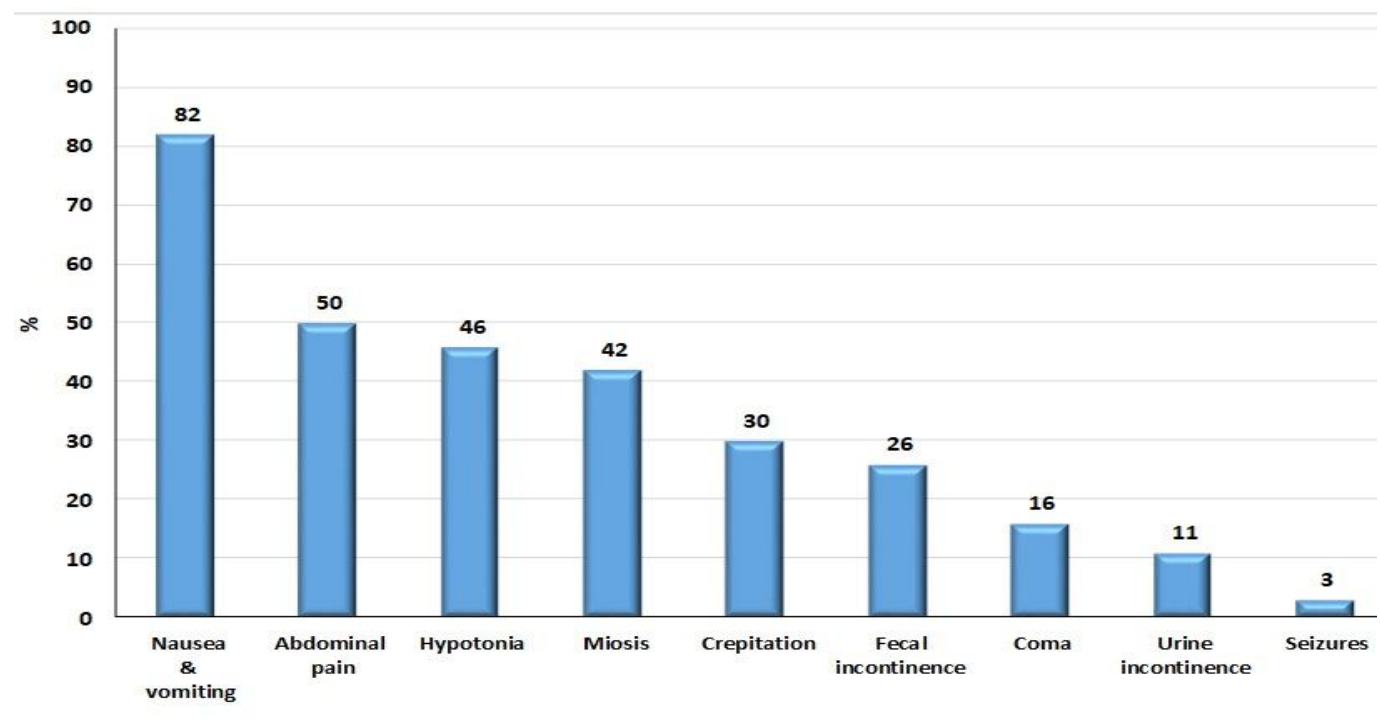

Fig. (2): Clinical manifestations in the studied patients.

Table (2) compares between the studied scores on admission in MV and non-MV patients as well as between survivors and nonsurvivors. All the median scores were significantly higher in MV-patients than in the non-MV, while GCS was significantly lower in the MV-patients than the non-MV patients $(p<0.001)$. The same findings were found on comparing the survivors with non- survivors.

Table (2): Comparison of the studied scoring systems between intubated and non-intubated patients as well as survivors and non-survivors in the studied patients $(\mathrm{n}=118)$ :

\begin{tabular}{|c|c|c|c|c|c|c|c|c|c|c|}
\hline & \multicolumn{5}{|c|}{ Mechanical ventilation (MV) } & \multicolumn{5}{|c|}{ Mortality } \\
\hline & \multicolumn{2}{|r|}{ No } & \multicolumn{2}{|c|}{ Yes } & \multirow[b]{2}{*}{$\mathbf{p}$} & \multicolumn{2}{|c|}{ Survivors } & \multicolumn{2}{|c|}{ Non-survivors } & \multirow{2}{*}{$\mathbf{p}$} \\
\hline & $\mathbf{M}$ & IQR & $\mathbf{M}$ & IQR & & $\mathbf{M}$ & IQR & $\mathbf{M}$ & IQR & \\
\hline APACHEII & 4 & $2-7$ & 17 & $14-20$ & $<0.001^{*}$ & 5 & $2-8$ & 15 & $10-20$ & $<0.001^{*}$ \\
\hline GCS & 15 & $15-15$ & 6 & $5-11$ & $<0.001^{*}$ & 15 & $15-15$ & 7 & $5-13$ & $<0.001^{*}$ \\
\hline RAPS & 3 & $1-4$ & 11 & $7-12$ & $<0.001^{*}$ & 3 & $2-5$ & 11 & $7-13$ & $<0.001^{*}$ \\
\hline REMS & 3 & $1-4$ & 11 & $7-12$ & $<0.001^{*}$ & 3 & $2-5$ & 10 & $7-12$ & $<0.001^{*}$ \\
\hline SCS & 2 & $0-3$ & 6 & $5-7$ & $<0.001^{*}$ & 2 & $0-4$ & 6 & $5-6$ & $<0.001^{*}$ \\
\hline
\end{tabular}

APACHE II: acute physiology and chronic health evaluation; GCS: Glasgow Coma Scale; RAPS: rapid acute physiology score; REMS: rapid emergency medicine score; SCS: simple clinical score; M: median; IQR: interquartile range; * $\mathrm{p}$ is significant at $<0.05$.

Table (3) and figure (3) show the ROC curve analysis for the prediction of the need for MV using the studied scoring systems. All the studied scores had an AUC of 0.9 - which indicate their being very good to excellent predictors. The REMS had the best AUC (AUC $=0.983,95 \% \mathrm{CI}=0.962-1.000$ ), followed by RAPS score (AUC $=0.982,95 \% \mathrm{CI}=0.961$ 1.000), then APACHE II (AUC $=0.969,95 \%$ $\mathrm{CI}=0.939-1.000), \quad$ GCS $\quad(\mathrm{AUC}=0.921, \quad 95 \%$
$\mathrm{CI}=0.857-0.963$ ), and SCS (AUC $=0.918$, 95\% CI $=0.859-0.978)$. The AUCs of REMS and RAPS were significantly higher than that of SCS. There was no statistically significant difference among the AUCs of APACHE II, GCS, RAPS, and REMS. The optimal cut-off values for each score and their associated sensitivities, specificities, PPV, and NPP are demonstrated in table (3). 
Table (3): Comparison of the studied scores for prediction of the need for mechanical ventilation using ROC curve analysis $(\mathrm{n}=118)$ :

\begin{tabular}{|l|c|c|c|c|c|}
\hline & APACHE II & GCS & RAPS & REMS & SCS \\
\hline AUC & 0.969 & 0.921 & 0.982 & 0.983 & 0.918 \\
$(\mathbf{9 5 \%}$ CI) & $(0.939-1.000)$ & $(0.857-0.963)$ & $(0.961-1.000)$ & $(0.962-1.000)$ & $(0.859-0.978)$ \\
\hline p & $<0.001^{*}$ & $<0.001^{*}$ & $<0.001^{*}$ & $<0.001^{*}$ & $<0.001^{*}$ \\
\hline Cut off value & $>9$ & $\leq 13$ & $>6$ & $>6$ & $>3$ \\
\hline Sensitivity \% & 94 & 88 & 94 & 94 & 94 \\
\hline Specificity \% & 91 & 96 & 95 & 96 & 76 \\
\hline PPV \% & 64 & 79 & 76 & 80 & 40 \\
\hline NPV \% & 99 & 98 & 99 & 99 & 99 \\
\hline Pairwise comparisons & \multicolumn{5}{|l|}{} \\
\hline APACHE II & 0.161 & 0.161 & 0.366 & 0.336 & 0.096 \\
\hline GCS & 0.3660 & 0.164 & 0.164 & 0.160 & 0.958 \\
\hline RAPS & 0.3363 & 0.160 & 0.627 & 0.627 & $0.037^{*}$ \\
\hline REMS & 0.0962 & 0.958 & $0.037^{*}$ & $0.034^{*}$ & $0.034^{*}$ \\
\hline SCS &
\end{tabular}

APACHE II: acute physiology and chronic health evaluation; GCS: Glasgow Coma Scale; RAPS: rapid acute physiology score; REMS: rapid emergency medicine score; SCS: simple clinical score; PPV: positive predictive value; NPV: negative predictive value; ROC: receiver operating characteristic; AUC: area under the curve; CI: confidence interval; * $\mathrm{p}$ is significant at $<0.05$.
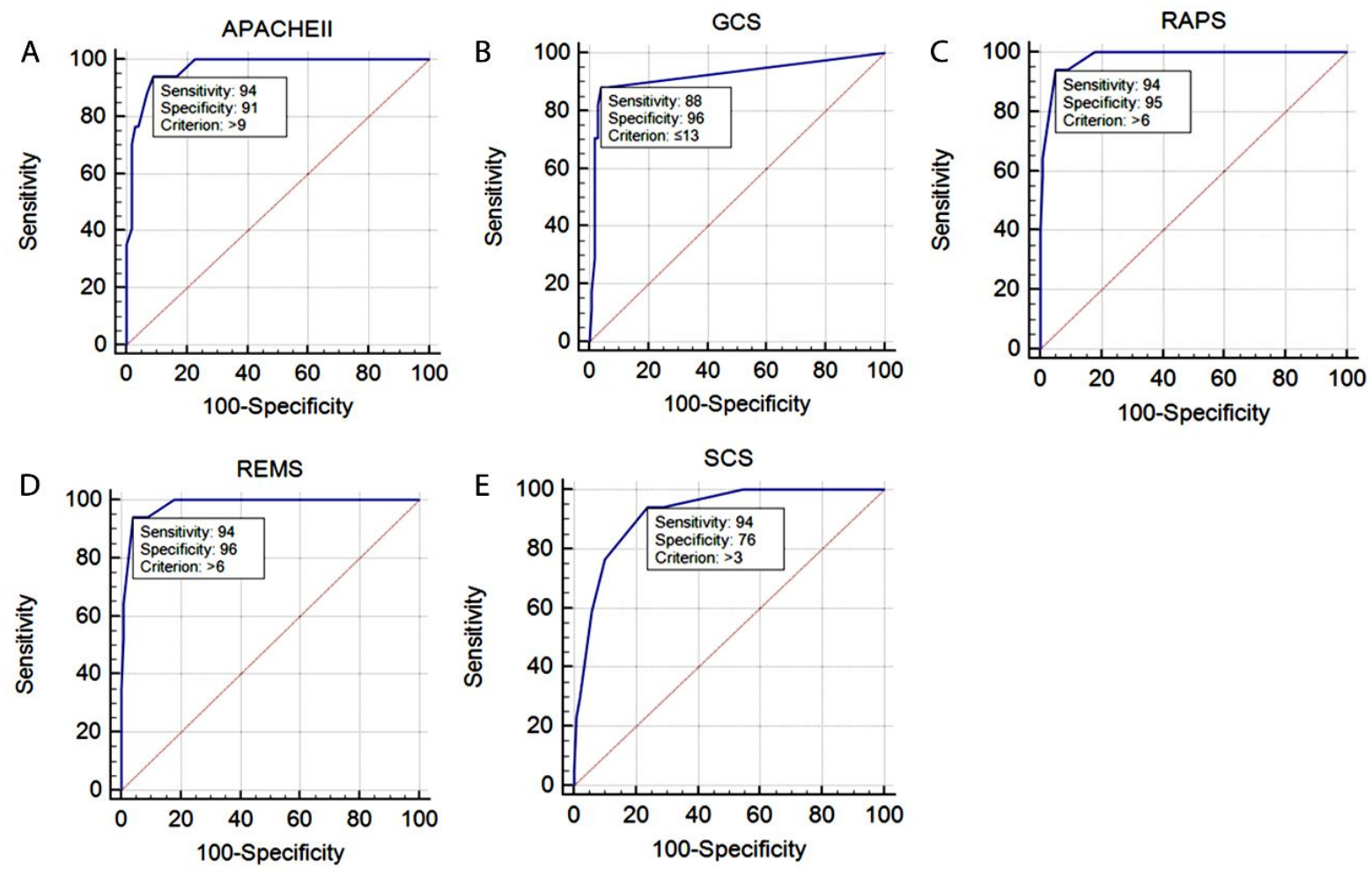

Fig. (3): ROC curves for prediction of the need of mechanical ventilation using APACHE II score (A), GCS (B), RAPS (C), REMS (D) and SCS (E). APACHE II: acute physiology and chronic health evaluation; GCS: Glasgow Coma Scale; RAPS: rapid acute physiology score; REMS: rapid emergency medicine score; SCS: simple clinical score. 
Table (4) and figure (4) present the ROC curve analysis for the prediction of mortality using the studied scoring systems. All the studied scores had an AUC of 0.8 to 0.9 which indicate their being very good to excellent predictors for mortality. RAPS score had the best AUC (AUC $=0.925, \quad 95 \%$ $\mathrm{CI}=0.864-0.987$ ), followed by REMS score (AUC $=0.920,95 \% \mathrm{CI}=0.859-0.981$ ), then SCS
(AUC $=0.896,95 \% \mathrm{CI}=0.828-0.963), \mathrm{APACHE}$ II (AUC $=0.895,95 \% \quad \mathrm{CI}=0.818-0.972)$, and finally GCS $\quad(\mathrm{AUC}=0.867,95 \% \quad \mathrm{CI}=0.793$ 0.923). However, there was no statistically significant difference among the AUCs of the studied scores (all $\mathrm{p}$ values $>0.05$ ). The optimal cut-off values for each score and their associated sensitivities, specificities, PPV, and NPP are summarized in table (4).

Table (4): Comparison of the studied scores for prediction of mortality in OP-poisoned patients using ROC curve analysis $(\mathrm{n}=118)$ :

\begin{tabular}{|c|c|c|c|c|c|}
\hline & APACHE II & GCS & RAPS & REMS & SCS \\
\hline $\begin{array}{l}\text { AUC } \\
(95 \% \text { CI })\end{array}$ & $\begin{array}{c}0.895 \\
(0.818-0.972)\end{array}$ & $\begin{array}{c}0.867 \\
(0.793-0.923)\end{array}$ & $\begin{array}{c}0.925 \\
(0.864-0.987)\end{array}$ & $\begin{array}{c}0.920 \\
(0.859-0.981)\end{array}$ & $\begin{array}{c}0.896 \\
(0.828-0.963)\end{array}$ \\
\hline $\mathbf{p}$ & $<0.001 *$ & $<0.001 *$ & $<0.001^{*}$ & $<0.001 *$ & $<0.001 *$ \\
\hline Cut off value & $>7$ & $\leq 13$ & $>4$ & $>4$ & $>4$ \\
\hline Sensitivity \% & 100 & 86 & 100 & 100 & 86 \\
\hline Specificity \% & 70 & 88 & 75 & 75 & 85 \\
\hline PPV \% & 18 & 32 & 20 & 20 & 26 \\
\hline NPV \% & 100 & 99 & 100 & 100 & 99 \\
\hline \multicolumn{6}{|c|}{ Pairwise comparisons } \\
\hline APACHE II & & 0.571 & 0.920 & 0.426 & 0.986 \\
\hline GCS & 0.571 & & 0.440 & 0.488 & 0.651 \\
\hline RAPS & 0.920 & 0.440 & & 0.469 & 0.406 \\
\hline REMS & 0.426 & 0.488 & 0.469 & & 0.533 \\
\hline SCS & 0.986 & 0.651 & 0.406 & 0.533 & \\
\hline
\end{tabular}

APACHE II: acute physiology and chronic health evaluation; GCS: Glasgow Coma Scale; RAPS: rapid acute physiology score; REMS: rapid emergency medicine score; SCS: simple clinical score; PPV: positive predictive value; NPV: negative predictive value; ROC: receiver operating characteristic; AUC: area under the curve; CI: confidence interval; ${ }^{*} \mathrm{p}$ is significant at $<0.05$. 

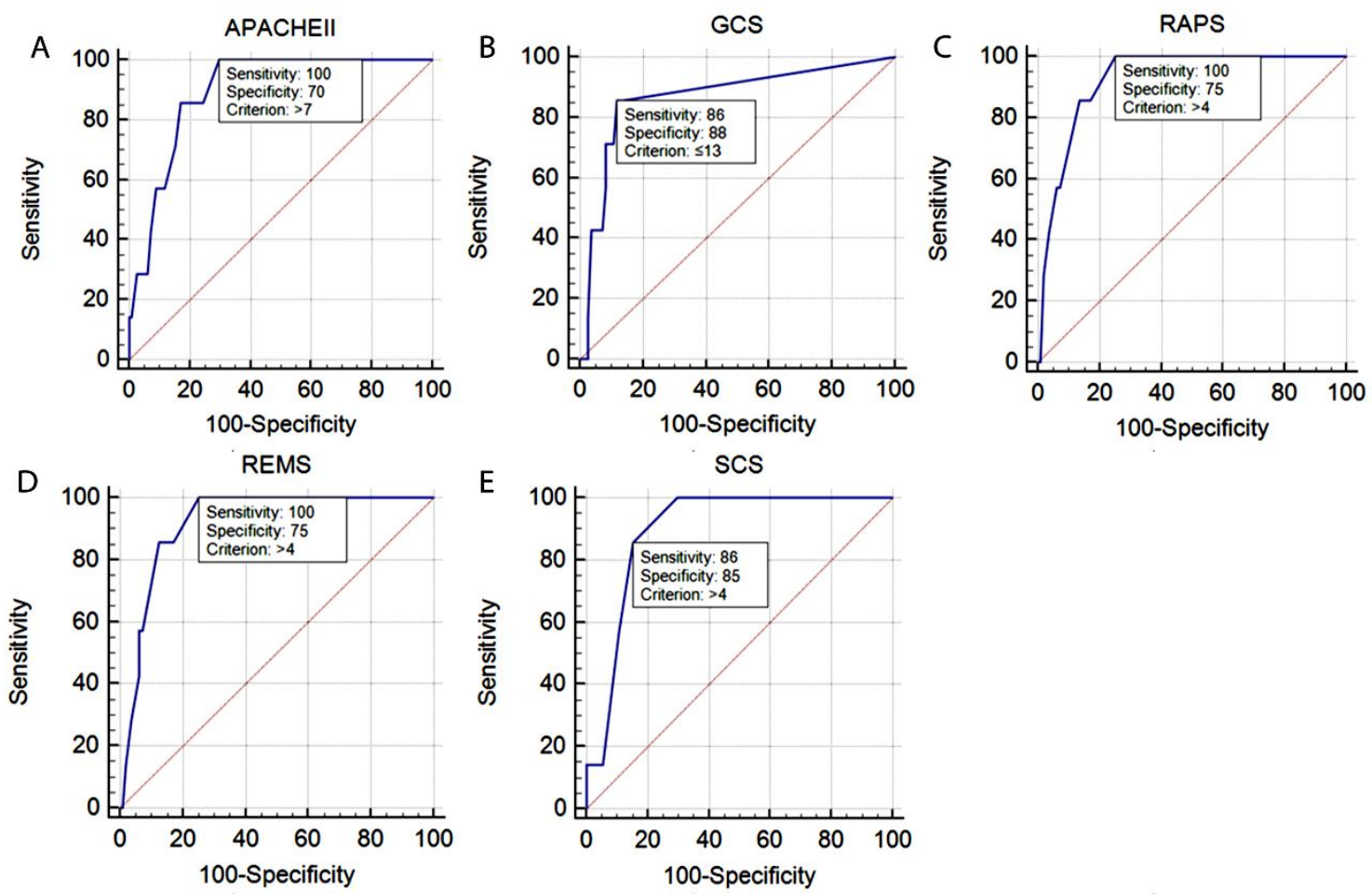

Fig. (4): ROC curves for prediction of mortality using APACHE II score (A), GCS (B), RAPS (C), REMS (D) and SCS (E). APACHE II: acute physiology and chronic health evaluation; GCS: Glasgow Coma Scale; RAPS: rapid acute physiology score; REMS: rapid emergency medicine score; SCS: simple clinical score.

Table (5) reveals that all the studied scoring systems correlated significantly and positively with the length of hospital stay (except for
GCS that correlated negatively); though the correlations were weak or moderate (correlation coefficients were 0.3 or less).

Table (5): Correlations between hospital stay and the studied scoring systems (total $n=118$ ):

\begin{tabular}{|l|c|c|}
\hline \multirow{3}{*}{ APACHEII } & & Length of hospital stay \\
\hline \multirow{3}{*}{ GCS } & $\mathbf{r}_{\mathbf{s}}$ & 0.241 \\
\cline { 2 - 3 } & $\mathbf{p}$ & $0.009^{*}$ \\
\hline \multirow{3}{*}{ RAPS } & $\mathbf{r}_{\mathbf{s}}$ & -0.308 \\
\cline { 2 - 3 } & $\mathbf{p}$ & $0.001^{*}$ \\
\hline \multirow{3}{*}{ REMS } & $\mathbf{r}_{\mathbf{s}}$ & 0.219 \\
\cline { 2 - 4 } & $\mathbf{p}$ & $0.017^{*}$ \\
\hline \multirow{3}{*}{ SCS } & $\mathbf{r}_{\mathbf{s}}$ & 0.222 \\
\cline { 2 - 3 } & $\mathbf{p}$ & $0.016^{*}$ \\
\hline
\end{tabular}

$\mathrm{r}_{\mathrm{s}}$ : correlation coefficient of Spearman's rank-order correlation; * significant at $\mathrm{p}<0.05$. 
Table (6): Previous scoring systems in OP poisoning:

\begin{tabular}{|c|c|c|c|c|c|c|c|c|}
\hline Study & $\begin{array}{c}\text { Scoring } \\
\text { system }\end{array}$ & Study type & $\begin{array}{c}\text { Total } \\
\mathbf{n}\end{array}$ & $\begin{array}{c}\text { MV } \\
\text { n (\%) }\end{array}$ & AUC & Cut-off & $\begin{array}{c}\text { Sensitivity } \\
(\%)\end{array}$ & $\begin{array}{c}\text { Specificity } \\
(\%)\end{array}$ \\
\hline $\begin{array}{l}\text { Grmec et } \\
\text { al.(2004) }\end{array}$ & GCS & Prospective & 65 & $34(52 \%)$ & 0.92 & $\leq 6$ & 84 & 89 \\
\hline $\begin{array}{l}\text { Eizadi-Mood } \\
\text { et al. }(2007)\end{array}$ & APACHE II & Retrospective & 131 & $6(5 \%)$ & 0.902 & $>7$ & 79 & 83 \\
\hline Study & $\begin{array}{l}\text { Scoring } \\
\text { system }\end{array}$ & Study type & $\begin{array}{c}\text { Total } \\
\mathbf{n}\end{array}$ & $\begin{array}{l}\text { Deaths } \\
\text { n (\%) } \\
\end{array}$ & AUC & Cut-off & $\begin{array}{c}\text { Sensitivity } \\
(\%) \\
\end{array}$ & $\begin{array}{c}\text { Specificity } \\
(\%) \\
\end{array}$ \\
\hline $\begin{array}{l}\text { Grmec et } \\
\text { al.(2004) }\end{array}$ & GCS & Prospective & 65 & $14(22 \%)$ & 0.88 & $\leq 6$ & 70 & 87 \\
\hline \multirow{2}{*}{$\begin{array}{l}\text { Bilgin et al. } \\
\text { (2005) }\end{array}$} & GCS & Retrospective & 32 & $7(22 \%)$ & 0.90 & $<9$ & 86 & 72 \\
\hline & APACHE II & & & & 0.93 & $>16$ & 100 & 80 \\
\hline \multirow{2}{*}{$\begin{array}{l}\text { Sungurtekin } \\
\text { et al. (2006) }\end{array}$} & GCS & Retrospective & 48 & $11(23 \%)$ & 0.725 & $<9$ & 64 & 78 \\
\hline & APACHE II & & & & 0.791 & $\geq 11$ & 90 & 60 \\
\hline $\begin{array}{l}\text { Davies et al. } \\
(2008)\end{array}$ & GCS & Prospective & 1365 & $184(13 \%)$ & 0.84 & $\leq 13$ & 79 & 79 \\
\hline Sarhan (2015) & APACHE II & Prospective & 73 & $28(38 \%)$ & 0.777 & $>10.5$ & 54 & 98 \\
\hline $\begin{array}{l}\text { Wu et al. } \\
(2016)\end{array}$ & APACHE II & Prospective & 100 & $\begin{array}{c}\text { Not } \\
\text { mentioned }\end{array}$ & 0.72 & $\geq 10.5$ & $>90 \%$ & $>90 \%$ \\
\hline $\begin{array}{l}\text { Moussa et al. } \\
(2018 b)\end{array}$ & APACHE II & $\begin{array}{l}\text { Retrospective } \\
\text { \&prospective }\end{array}$ & 200 & $20(10 \%)$ & 0.986 & $>10$ & 100 & 91 \\
\hline $\begin{array}{l}\text { Yuan et al. } \\
(2018)\end{array}$ & APACHE II & Retrospective & 59 & 9 & 0.876 & $\geq 13.5$ & 100 & 71 \\
\hline
\end{tabular}

APACHE II: acute physiology and chronic health evaluation; AUC: area under the curve; GCS: Glasgow Coma Scale; MV: mechanical ventilation.

\section{Discussion}

Several scoring systems were studied in AChEIs-poisoned patients, including APACHE II, GCS, SOFA, SAPS and other scoring systems. However, none of the previous studies has evaluated the use of emergency scores at hospital admission to predict the probability of mortality or the need for MV. Up to the best of the authors' knowledge, this study is the first to compare between different physiological and emergency scores to predict outcome in patients with AChEIs poisoning.
The present study showed that the age, gender, route, manner of poisoning and clinical presentation of the studied patients were more or less in agreement with the findings of the majority of studies both in Egypt and across the world (Pajoumand et al., 2004; Sungurtekin et al., 2006; Amiri and Mahmoudi, 2008; Gannur et al., 2008; Ibrahim et al., 2011; Banerjee et al., 2012; Kale, 2013; Rajeev and Arvind, 2013; Hafez and Beltagy, 2016).

The most common cause of death in patients with AChEI poisoning is respiratory 
failure as it affects up to $70 \%$ of cases (Lee and Tai, 2001; Sungur and Güven, 2001). Respiratory failure may occur in patients with AChEI poisoning due to the aspiration of gastric contents, excessive secretions, and pneumonia (Grmec et al., 2004). Fortunately, death from respiratory failure can be prevented by early identification of patients at risk and intervention with prompt endotracheal intubation and MV (Grmec et al., 2004).

In the present study, MV was required in only $14 \%$ of cases, which is similar to the rate of $11 \%$ reported by $\mathrm{Wu}$ et al. (2016). However, higher rates - ranging from $21 \%$ up to $52 \%$ were reported by previous studies (Grmec et al., 2004; Eddleston et al., 2006; Lee et al., 2014; Muley et al., 2014; Dündar et al., 2015; Acikalin et al., 2017). A much lower rate (5\%) was reported by Eizadi-Mood et al. (2007). These variations in the reported incidence of MV-poisoned patients may be due to differences in the severity of poisoning in the studied samples.

On comparison of the median scores on admission between patients who were later MV and those that were not, we found a significant difference between the two groups. This indicates a potential role for these scoring systems in predicting the need of MV.

In the present study, the median APACHE II score was 4 in non-MV and 17 in MV patients. The median GCS was 15 in nonMV, while it was 6 in the MV. Previous studies on AChEI-poisoned patients reported similar findings as regards GCS and APACHE II. Eizadi-Mood et al. (2007) found the median APACHE II score to be 4 in non-MV survivors, 14 in MV survivors and 18 in MV non-survivors. Acikalin et al. (2017) found that the mean GCS was 15 in non- MV patients and 8 in MV-patients. Grmec et al. (2004) stated that the median GCS was 6 in patients with respiratory failure and 10 in those without. On the other hand, Sam et al. (2009) found no association between the GCS scores and the need for MV.

The RAPS and REMS scores were evaluated as predictors of the need of MV in poisoning with many agents, but not ACHEIs. El-Sarnagawy and Hafez (2017) studied REMS, RAPS, APACHE II and GCS in drug overdose patients presenting with disturbed consciousness. They found the median RAPS and REMS to be significantly higher in MV patients than in the non-MV (6 versus 4 and 9 versus 4 , respectively).

The accuracy of the studied scoring systems as predictors of the need for MV was then evaluated in this study using ROC curve analysis. We found that REMS showed the best discriminatory power, followed by RAPS, APACHE II, and GCS, with no significant differences between them. Only SCS showed a significantly lower accuracy than REMS and RAPS. These findings suggest that the emergency scoring systems that are relatively simple and rapid (i.e., GCS, RAPS and REMS) can be used to prioritize patients who are in need of MV, other than the more complicated, time consuming physiological scoring systems (i.e. APACHE II).

The results of previous studies that evaluated the same scores we studied are summarized in table (6). Only one previous study (Eizadi-Mood et al., 2007) assessed APACHE II score as a predictor of MV in OPCs poisoned patients and found a lower AUC (0.902), cut-off value ( $>7)$, sensitivity (79\%) and specificity (83\%) of APACHE II than in the present study. Also, one previous study has evaluated GCS (Grmec et al., 2004) and found similar accuracy to our results (AUC $=0.92)$ but with lower cut-off value $(\leq 6)$, sensitivity (84\%) and specificity (89\%). These differences in the cut-off value may be attributed to different grades of poisoning severity. Also, the criteria of MV may differ 
from one hospital to another depending on the treatment protocols in each hospital.

Both REMS and RAPS scores in the present study had excellent predictive accuracy of the need of MV. El-Sarnagawy and Hafez (2017) reported a less, but fair, predictive accuracy in their study of overdose patients.

As regards the mortality in AChEIpoisoned patients, $6 \%$ of patients died in this study. The reported mortality following AChEI poisoning ranged from 3 up to $46 \%$ (Sungur and Güven, 2001; Verhulst et al., 2002; Godhwani et al., 2004; Bilgin et al., 2005; Dharmani and Jaga, 2005; Sungurtekin et al., 2006; Bilal et al., 2014; Moussa et al., 2018a).

On comparison of the median scores on admission between the survivors and nonsurvivors, a significant difference was found between the two groups, suggesting their potential role in predicting the patients' risk of mortality.

The median GCS in the present study was 15 in survivors, while it was 7 in the nonsurvivors. These results were in line with Churi et al. (2012) and Muley et al. (2014) who reported a mean of 13 in survivors and 7 in non-survivors. Also, Moussa et al. (2018a) found the mean GCS values to be 14 and 5 for survivors and non-survivors respectively. Cander et al. (2011) reported a similar value in survivors $($ mean $=15)$ but a much lower value in non-survivors (mean $=3$ ). The median APACHE II score in the current study was 5 in survivors and 15 in non-survivors. This is partially in line with Churi et al. (2012) who found the mean score to be 6 in survivors and 23 in non-survivors. Moreover, Moussa et al. (2018a) reported the mean APACHE II to be 5 in survivors and 23 in non-survivors.

The REMS and RAPS scores were evaluated as predictors of mortality in different types of poisonings, but not in ACHEIs poisoned cases. The SCS has not been evaluated in poisoned patients before.

We evaluated the ability of the studied scoring systems to predict mortality. RAPS score had the best discriminatory power, followed by REM, SCS, APACHE II, and GCS in that order.

The discriminatory power of APACHE II score in this study was good for prediction of mortality (AUC $=0.895)$, with the optimal cutoff value $>7$ and $100 \%$ sensitivity, $70 \%$ specificity, 18\% PPV, and 100\% NPV. As for GCS, the discriminatory power was 0.867 , with $86 \%$ sensitivity, $88 \%$ specificity, $32 \%$ PPV, and $99 \% \mathrm{NPV}$ at a cut-off point $\leq 13$. Higher accuracy was reported for APACHE II (Bilgin et al., 2005; Moussa et al., 2018b) and for GCS (Grmec et al., 2004; Bilgin et al., 2005). Lower accuracy was reported also by previous studies for APCHE II (Sungurtekin et al., 2006; Wu et al., 2016; Yuan et al., 2018) and GCS (Sungurtekin et al., 2006; Davies et al., 2008).

Moreover, the cut-off value and its associated sensitivity, specificity, PPV and NPV varied greatly between the different studies. The cut-off value of GCS was lower in most of the previous studies, ranging between 6 and 9 (Grmec et al., 2004; Bilgin et al., 2005; Sungurtekin et al., 2006) and was 13 - similar to our results - in one study (Davies et al., 2008). As for APACHE II, the cut-off point was higher in the previous studies, ranging from 10 to 16 (Bilgin et al., 2005; Sungurtekin et al., 2006; Wu et al., 2016; Moussa et al., 2018b; Yuan et al., 2018).

In addition, Yen et al. (2000) reported that significantly higher APACHE II scores and lower GCS were highly suggestive of poor prognostic outcome. Lee and Tai (2001) suggested that the mortality rate is almost $100 \%$ when the patients had an APACHE II score over 26 . However, the very small number of non-survivors in their study (3 out of 23) 
rendered them unable to give a reliable conclusion.

The current study has found no significant difference between the studied scores as predictors of the need of MV and the occurrence of mortality. This indicates that the emergency scores are comparable to APACHE II score and can be used as a tool to identify patients with AChEI poisoning who are at increased risk of mortality, in order to provide them with urgent and prompt treatment or transport them to better facilities. This inference is supported by the results of two studies that have compared GCS with APACHE II and simplified acute physiology score (SAPS) II (Bilgin et al., 2005; Sungurtekin et al., 2006) and reported the lack of significant differences between their AUCs. This lack of significant difference in discriminatory power between APACHE II and clinical scores was also reported by previous studies which evaluated other poisons. ElSarnagawy and Hafez (2017) have reported the lack of significant difference between the AUCs of APACHE II, GCS, REMS and RAPS as predictors of MV in drug overdose patients. Moreover, Abd Elghany et al. (2018) compared REMS - as a predictor of mortality - to APACHE II and SOFA scores in patients poisoned with aluminium phosphide. They found that REMS had an AUC of 0.970 and did not differ significantly from the other two scores.

In the current study, all the studied scoring systems correlated significantly and positively with the length of hospital stay, though the correlations were weak or moderate. This finding is in line with Moussa et al. (2018b) who found that APACHE II is correlated moderately with the length of hospital stay. In contrast to the results of the present study, Cander et al. (2011) reported the lack of significant correlation between GCS and hospital stay.

\section{Limitations}

This study was subject to some limitations. Being a single-center study, our results may not be representative of all AChEIpoisoned patients. Also, we were unable to identify the exact AChEI compound used in every patient in order to compare the scores between the different AChEI compounds.

\section{Conclusion}

In conclusion, the on-admission REMS or RAPS seem to have valuable prognostic abilities in acute AChEI poisoning for identification of patients who may require MV or are at increased risk of mortality. Future studies are needed on larger sample sizes to validate their use in AChEI-poisoned patients and to ascertain the best cut-off value for prediction.

\section{Acknowledgments}

The authors express their sincere gratitude for all the staff of the TUPCC for their co-operation during the study period and their helping in data retrieval from patients' files.

\section{References}

Abd Elghany, S.A.; Heshmat, M.M.; Oreby, M.; et al. (2018): "Evaluation of various scoring systems in prediction of acute aluminum phosphide (ALP) poisoning outcome". Ain-Shams J. Forensic Med. Clin. Toxicol., 30:117-127.

Acikalin, A.; Dişel, N.R.; Matyar, S.; et al. (2017): "Prognostic factors determining morbidity and mortality in organophosphate poisoning". Pak. J. Med. Sci., 33 (3):534-539.

Akdur, O.; Durukan, P.; Ozkan, S.; et al. (2010): "Poisoning severity score, 
Glasgow coma scale, corrected QT interval in acute organophosphate poisoning". Hum. Exp. Toxicol., 29 (5): 419-425.

Amiri, A.H. and Mahmoudi, G.A. (2008): "Analysis of organophosphosphates intoxicated cases treated at Khorramabad and Sari, Iran". Res. J. Biol. Sci., 3 (7):775-778.

Banerjee, I.; Tripathi, S. and Roy, A.S. (2012): "Clinico - epidemiological characteristics of patients presenting with organophosphorus poisoning". N. Am. J. Med. Sci., 4 (3):147-150.

Bilal, M.; Khan, Y.; Ali, S.; et al. (2014): "The pattern of organophosphorus poisoning and it's short term outcomes in various socioeconomic groups". KJMS., 7 (1):11-16.

Bilgin, T.E.; Camdeviren, H.; Yapici, D.; et al. (2005): "The comparison of the efficacy of scoring systems in organophosphate poisoning" Toxicol. Ind. Health, 21 (5-6):141-146.

Brabrand, M.; Folkestad, L.; Clausen, N.G.; et al. (2010): "Risk scoring systems for adults admitted to the emergency department: a systematic review". Scand. J. Trauma Resusc. Emerg. Med., 18 (1):1-8.

Buckley, N.A.; Eddleston, M.; Li, Y.; et al. (2011): Oximes for acute organophosphate pesticide poisoning. Cochrane Database Syst. Rev. Available at:https://www.cochranelibrary.com/cdsr/ doi/10.1002/14651858.CD005085.pub2/f ull. Accessed December 4, 2018.

Buckley, N.A.; Roberts, D. and Eddleston, M. (2004): "Overcoming apathy in research on organophosphate poisoning". BMJ, 329 (7476):1231-1233.
Cander, B.; Dur, A.; Yildiz, M.; et al. (2011): "The prognostic value of the Glasgow coma scale, serum acetylcholinesterase and leukocyte levels in acute organophosphorus poisoning". Ann. Saudi Med., 31 (2):163-166.

Churi, S.; Bhakta, K. and Madhan, R. (2012): "Organophosphate poisoning: prediction of severity and outcome by Glasgow coma scale, poisoning severity score, acute physiology and chronic health evaluation II score, and simplified acute physiology score II". J. Emerg. Nurs., 38 (5):493-495.

Davies, J.O.; Eddleston, M. and Buckley, N.A. (2008): "Predicting outcome in acute organophosphorus poisoning with a poison severity score or the Glasgow coma scale". QJM-Int. J. Med., 101 (5):371-379.

Dawson, B. and Trapp, R.G. (2001): Basic \& Clinical Biostatistics. Third edition. Lange Medical Book/McGraw-Hill, Medical Publishing Division, New York, NY, USA, P.P.161-218.

DeLong, E.R.; DeLong, D.M. and ClarkePearson, D.L. (1988): "Comparing the areas under two or more correlated receiver operating characteristic curves: a nonparametric approach". Biometrics, 44 (3):837-845.

Dharmani, C. and Jaga, K. (2005): "Epidemiology of acute organophosphate poisoning in hospital emergency patients". Rev. Environ. Health, 20 (3):215-232.

Dündar, Z.D.; Köylü, R.; Ergin, M.; et al. (2015): "Prognostic value of red cell distribution width in patients with organophosphate poisoning". J. Acad. Emerg. Med., 14 (2): 65-69. 
Eddleston, M.; Mohamed, F.; Davies, J.O.; et al. (2006): "Respiratory failure in acute organophosphorus pesticide selfpoisoning". QJM, 99 (8):513-522.

Eizadi-Mood, N.; Saghaei, M. and Jabalameli, M. (2007): "Predicting outcomes in organophosphate poisoning based on APACHE II and modified APACHE II scores". Hum. Exp. Toxicol., $26(7): 573-578$.

El-Sarnagawy, G.N. and Hafez, A.S. (2017): "Comparison of different scores as predictors of mechanical ventilation in drug overdose patients". Hum. Exp. Toxicol., 36 (6):539-546.

Gannur, D.; Maka, P. and Reddy, K. (2008): "Organophosphorus compound poisoning in Gulbarga region-A five year study". Indian J. Forensic Med. Toxicol, 2 (1):311.

Ghosh, A.K. and Brindisi, M. (2015): "Organic carbamates in drug design and medicinal chemistry . J. Med. Chem., 58 (7):2895-2940.

Godhwani, S.; Godhwani, S. and Tulsiani, K. (2004): "Management of organic insecticide poisoning in intensive care unit (ICU)". Indian J. Anaesth., 48 (4):295-295.

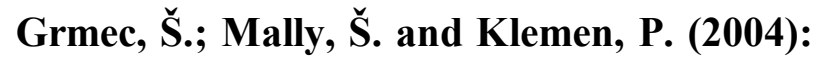
"Glasgow coma scale score and QTc interval in the prognosis of organophosphate poisoning". Acad. Emerg. Med., 11 (9):925-930.

Hafez, A.S. and Beltagy, D.M. (2016): "Comparison between serum Butyrylcholinesterase and $\beta$-Glucuronidase activities as indicators of severity and predictors of outcome in organophosphorous poisoning". AinShams J. Forensic Med. Clin. Toxicol., 27:125-134.
Ibrahim, M.A.; El Masry, M.K.; Moustafa, A.A.; et al. (2011): "Comparison of the accuracy of two scoring systems in predicting the outcome of organophosphate intoxicated patients admitted to intensive care unit (ICU)". Egypt. J. Forensic Sci., 1 (1):41-47.

Kale, B. (2013): "B-Glucuronidase as a new potent biomarker in the diagnosis and prognosis of organophosphorus toxicity." . Int. J. Biol. Res., 1 (1):5-9.

Khurana, D. and Prabhakar, S. (2000): "Organophosphorus intoxication". Arch. Neurol., 57 (4):600-602.

Knaus, W.A.; Draper, E.A.; Wagner, D.P.; et al. (1985): "APACHE II: a severity of disease classification system". Crit. Care Med., 13 (10):818-829.

Konradsen, F. (2007): “Acute pesticide poisoning-a global public health problem . Dan. Med. Bull., 54:58-59.

Lee, D.H.; Jung, K.Y.; Choi, Y.H.; et al. (2014): "Body mass index as a prognostic factor in organophosphate-poisoned patients". Am. J. Emerg. Med., 32 (7):693-696.

Lee, P. and Tai, D.Y.H. (2001): "Clinical features of patients with acute organophosphate poisoning requiring intensive care". Intensive Care Med., 27 (4):694-699.

Minton, N.A. and Murray, V.S. (1988): "A review of organophosphate poisoning". Med. Toxicol. Adverse Drug Exp., 3 (5):350-375.

Moussa, M.E.; Mohamed, S.A.; Hilal, M.A.; et al. (2018a): "Predictive value of triage vital signs and conscious level for outcome evaluation in acutely organophosphate poisoned patients". AinShams J. Forensic Med. Clin. Toxicol., 31:33-40. 
Moussa, M.E.; Mohamed, S.A.; Hilal, M.A.; et al. (2018b): "The role of APACHE II, SOFA, serum amylase and lipase in assessment of severity and outcome of acute organophosphorus poisoning". AinShams J. Forensic Med. Clin. Toxicol., 31:41-50.

Muley, A.; Shah, C.; Lakhani, J.; et al. (2014): "To identify morbidity and mortality predictors in acute organophosphate poisoning" Indian J. Crit. Care Med., 18 (5):297-300.

Olsson, T.; Terént, A. and Lind, L. (2004): "Rapid emergency medicine score: a new prognostic tool for in - hospital mortality in nonsurgical emergency department patients". J. Intern. Med., 255 (5):579587.

Oprita, B.; Aignatoaie, B. and GaborPostole, D.A. (2014): "Scores and scales used in emergency medicine. Practicability in toxicology". J Med. Life, 7 (Spec Iss 3):4-7.

Pajoumand, A.; Shadnia, S.; Rezaie, A.; et al. (2004): "Benefits of magnesium sulfate in the management of acute human poisoning by organophosphorus insecticides". Hum. Exp. Toxicol., 23 (12):565-569.

Paudyal, B.P. (2008): "Organophosphorus poisoning". J. Nepal Med. Assoc., 47 (172):251-258.

Peter, J.V.; Thomas, L.; Graham, P.; et al. (2013): "Performance of clinical scoring systems in acute organophosphate poisoning". Clin. Toxicol., 51 (9):850854.

Rajeev, H. and Arvind, M. (2013): "Study of clinical and biochemical parameters in predicting the need for ventilator support in organophosphorus compound poisoning". J. Evol. Med. Dent. Sci., 2 (49):9555-9571.

Rhee, K.J.; Fisher, C.J. and Willitis, N.H. (1987): "The rapid acute physiology score". Am. J. Emerg. Med., 5 (4):278282.

Sam, K.G.; Kondabolu, K.; Pati, D.; et al. (2009): "Poisoning severity score, APACHE II and GCS: Effective clinical indices for estimating severity and predicting outcome of acute organophosphorus and carbamate poisoning". J. Forensic Leg. Med., 16 (5):239-247.

Sarhan, N.M. (2015): "APACHE II, SAPS II, and SOFA scoring systems used for predicting outcome in acute organophosphate intoxicated patients admitted to the intensive care unit-poison control center, Ain Shams University Hospitals (a prospective study)". Ain-Shams J. Forensic Med. Clin. Toxicol., 25:110119.

Subbe, C.P.; Jishi, F. and Hibbs, R.A.B. (2010): "The simple clinical score: a tool for benchmarking of emergency admissions in acute internal medicine". Clin. Med. (Lond.), 10 (4):352-357.

Suliman, M.I.; Jibran, R. and Rai, M. (2006): "The analysis of organophosphates poisoning cases treated at Bahawal Victoria hospital, Bahawalpur in 2000-2003". Pak. J. Med. Sci., 22 (3):244-249.

Sungur, M. and Güven, M. (2001): "Intensive care management of organophosphate insecticide poisoning". Crit. Care, 5 (4): 211-215.

Sungurtekin, H.; Gürses, E. and Balci, C. (2006): "Evaluation of several clinical scoring tools in organophosphate poisoned patients". Clin. Toxicol., 44 (2):121-126. 
Teasdale, G. and Jennett, B. (1974): "Assessment of coma and impaired consciousness: a practical scale". Lancet, 304 (7872):81-84.

Verhulst, L.; Waggie, Z.; Hatherill, M.; et al. (2002): "Presentation and outcome of severe anticholinesterase insecticide poisoning". Arch. Dis. Child., 86 (5):352355.

Wu, X.; Xie, W.; Cheng, Y.; et al. (2016): "Severity and prognosis of acute organophosphorus pesticide poisoning are indicated by C-reactive protein and copeptin levels and APACHE II score". Exp. Ther. Med., 11 (3):806-810.
Yen, D.H.; Yien, H.W.; Wang, L.M.; et al. (2000): "Spectral analysis of systemic arterial pressure and heart rate signals of patients with acute respiratory failure induced by severe organophosphate poisoning". Crit. Care Med., 28 (8):28052811.

Yuan, S.; Gao, Y.; Ji, W.; et al. (2018): "The evaluation of acute physiology and chronic health evaluation II score, poisoning severity score, sequential organ failure assessment score combine with lactate to assess the prognosis of the patients with acute organophosphate pesticide poisoning". Medicine (Baltimore), 97 (21):e10862. 


\section{مقارنة بين أنظمة قياسية مختلفة في التسمم بمثبطات الكولينستراز}

\section{مروة محمد شاهين و أمل سعيد أحمد فتحي حافظ}

قسم الطب الثرعى و السموم الإكلينيكية ـ كلية الطب - جامعة طنطا

يعتبر التحديد المبكر للمرضى المصابين بالتسمم بمثبطات الكولينستر از المعرضين لخطر قصور الجهاز

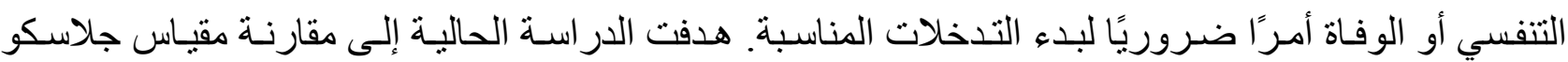
للغيبوبـة (GCS)، مقياس الفسيولوجيا الحـادة والصحة المزمنـة (مقياس أباتشي الثاني) ( APACHE II )، و مقياس الفسيولوجيا الحادة السريع (مقياس رابس) (RAPS)، ومقياس طب الطوارئ السريع (مقياس ريمس) ومقياس العلامات السريرية البسيط (RCS) من أجل التنبؤ بالحاجـة إلى التنفس الصناعي وحدوث (RAS)

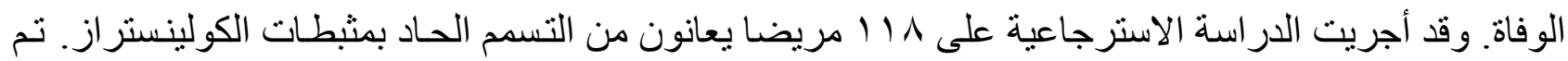
جمع بيانات المرضى من سجلات المستشفى الخاصة بهم. تم در اسة نظم التقييم المختارة عند دخول المستشفى.

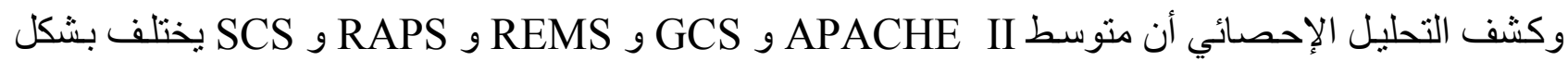
ذو دلالة احصائية بين المرضى الذين احتاجو التنفس صناعي و الذين لم يحتاجو الـه، وكذلك بين غير الناجين و الناجين. أظهرت نتائج RAMS و RAPS أعلى قوة تمييز في التتبؤ بالحاجة للتنفس الصناعي و الوفاة. تم الكثف عن عدم وجود فروق ذات دلالة إحصائية بين أنظمة التقييم التي تمت در استها كمتنبئات بالحاجة للتنفس فئس

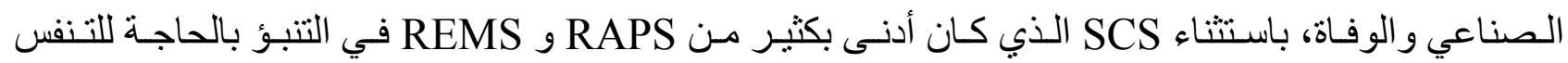
الصناعي. ونستتنج أنه يبدو أن أنظمـة التقييم REMS أو RAPS في وقت دخول المريض المبن المستشفى لديهم

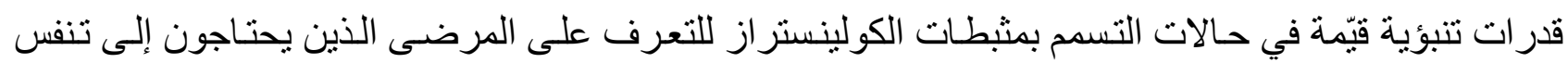
صناعي أو في خطر متز ايد للوفاة. 